D0I: 10.12957/demetra.2016.15443

\title{
A criatividade dos chefes de cozinha e o consumo moderno da gastronomia
}

\section{Chef's creativity and the modern gastronomy consumption}

Rita de Cássia Ribeiro

Rita de Cássia Marques²

Edgar Gastón Jacobs Flores Filho ${ }^{3}$

1 Universidade Federal de Minas Gerais, Departamento de Nutrição, Escola de Enfermagem. Belo Horizonte-MG, Brasil.

2 Universidade Federal de Minas Gerais, Departamento de Enfermagem Aplicada, Escola de Enfermagem. Belo Horizonte-MG, Brasil.

${ }^{3}$ Pontifícia Universidade Católica de Minas Gerais, Faculdade Mineira de Direito. Belo Horizonte-MG, Brasil.

Correspondência / Correspondence Rita de Cássia Ribeiro

E-mail: ritagastronomia@hotmail.com

\section{Resumo}

Neste ensaio, pretende-se discutir a comensalidade moderna das refeições, tendo como pano de fundo a gastronomia e o trabalho dos chefes de cozinha. Esses profissionais, por meio da formulação dos cardápios, possibilitam às pessoas comerem o que quiserem e experimentarem novos sabores, e favorecem a incorporação de novos modos alimentares. Portanto, o objetivo foi investigar e discutir o papel da criatividade dos chefes de cozinha na elaboração de cardápios e os impactos dessa ação no consumo de alimentos. Nesta investigação, foram realizadas entrevistas semiestruturadas com chefes de restaurantes à la carte localizados na região centro-sul de Belo Horizonte, Minas Gerais. As entrevistas foram realizadas até a saturação das informações e o tratamento e interpretação dos resultados obtidos permitiram estabelecer uma relação entre o conteúdo manifesto nos discursos e a literatura científica pertinente. O processo criativo dos chefes e, consequentemente, sua influência nos novos modos alimentares da contemporaneidade, pode indicar um novo percurso para os estudos relacionados ao comportamento alimentar. Constatouse que, em tempos de modernidade alimentar, a criatividade, a vivência pessoal e profissional e a emoção por ele provocada no cliente são fundamentos do trabalho do chefe de cozinha.

Palavras-chave: Restaurantes. Culinária. Consumo de alimentos. Criatividade. 


\section{Abstract}

In this essay we intend to discuss the modern table fellowship meals, with the backdrop of the food and the work of chefs. These professionals, through the formulation of the menus, enable people to eat whatever they want and to try new flavors, and favor the incorporation of new food modes. Therefore, the aim was to investigate and discuss the role of creativity of the chefs in preparing menus and the impacts of this action on food consumption. In this investigation were conducted semistructured interviews with heads of a la carte restaurants located in the south central region of Belo Horizonte, Minas Gerais state, Brazil. The interviews were conducted by the saturation of information and the processing and interpretation of results allowed to establishing a relationship between the manifest content in the discourse and the scientific literature. The creative process of the heads and therefore their influence on new modes of contemporary food, may indicate a new route for studies related to eating behavior. It was found that, in times of food modernity, creativity, personal and professional experience and the excitement caused by it on the client are foundations of the work of the chef.

Key words: Restaurants. Cooking. Food consumption. Creativity.

\section{Introdução}

No campo da cultura, observa-se que o restaurante, local privilegiado de comensalidade, tem se transformado em um lugar onde se buscam satisfação e facilidade. A casa não é mais o local eleito para as refeições, visto que, dia após dia, a rua ou ambientes fora do lar firmam-se como locais frequentes de alimentação. ${ }^{1-3}$ Esta situação é especialmente perceptível no contexto da modernidade alimentar, um momento peculiar, no qual o ato de consumir alimentos sofre grandes transformações devido às mudanças na sociedade contemporânea. ${ }^{4}$ Para exemplificar, de acordo com as tendências para os segmentos de alimentos e bebidas traçadas pelo Brasil Food Trends $2020,{ }^{5}$ estima-se que as pessoas passarão a fazer suas escolhas alimentares principalmente pautadas na sensorialidade e no prazer, com a valorização da gastronomia.

Sob a óptica social e cultural, a invenção da culinária se deu a partir da domesticação do fogo. $\mathrm{O}$ ato de cozinhar foi um dos grandes acontecimentos revolucionários da história, devido ao modo transformador da sociedade a partir da organização dos indivíduos em torno das refeições em conjunto e de horários de comer previsíveis. ${ }^{6}$ 
Após a invenção da culinária, o começo da produção sistemática de alimentos de origem animal ou vegetal foi outro grande marco e, a partir do momento que algumas pessoas começaram a controlar mais recursos alimentícios que as demais, a comida passou a ser um diferenciador social. O que importava era a quantidade, e não a seleção dos pratos ou a forma como eram preparados. Um apetite gigantesco normalmente era uma fonte de prestígio em quase todas as sociedades ${ }^{6}$ e há façanhas legendárias de digestão registradas na Antiguidade, na Idade Média e na Idade Moderna. ${ }^{7}$

No entanto, a quantidade por si só não poderia continuar a ser o único critério de uma dieta de prestígio, por isso o sabor, a variedade e a elegância passaram a ter efeito enobrecedor. Nesse sentido, as consequências da culinária socialmente diferenciada incluem o surgimento de uma profissão de alto nível com um aparato de técnicas e um código de práticas na cozinha, a do chefe. ${ }^{6}$

O chefe de cozinha é o personagem central do restaurante à la carte, que diferentemente das cozinhas de rua e das hospedarias comuns desde a Antiguidade, oferece um cardápio com diferentes opções que vai além de suprir a necessidade fisiológica do comer. Essa extensa lista de itens possibilita que as pessoas comam o que quiserem. ${ }^{8} \mathrm{O}$ cardápio é feito para seduzir, para instigar o gosto e levar à vontade de experimentar novos sabores.

Estima-se que os restaurantes, especialmente os à la carte, deverão se orientar para uma gastronomia mais específica e focar em jantares e refeições de lazer. Proença ${ }^{9}$ faz referência ao patamar atingido pelos restaurantes, como locais privilegiados de produção e partilha de cultura, assim como museus e teatros. Por isso, como um produtor de arte, o chefe de cozinha firma-se como um artista moderno.

A figura do chefe de cozinha apresenta-se como um agente que influencia as escolhas alimentares, o modo como as pessoas passam a ver o alimento e o ato de comer em si. Ele é o protagonista de um enredo que passa pela incorporação de novos modos alimentares pelos comensais.

Em uma sociedade pós-moderna, caracterizada pela fluidez dos conceitos, ${ }^{10}$ tratar da alimentação humana requer uma reflexão a respeito das transformações do comer e o trabalho do chefe de cozinha, nesse cenário, ganha cada vez mais espaço e importância. ${ }^{11}$ Portanto, o objetivo deste ensaio foi investigar e discutir o papel da criatividade dos chefes de cozinha na elaboração de cardápios e os impactos dessa ação no consumo de alimentos.

\section{Percurso metodológico}

Nesta investigação foram realizadas nove entrevistas semiestruturadas com chefes de restaurantes à la carte localizados na região centro-sul de Belo Horizonte, Minas Gerais, a de maior concentração de estabelecimentos com esse perfil de atendimento na cidade, segundo um 
guia de restaurantes publicado anualmente. As entrevistas foram realizadas até a saturação das informações, ou seja, até os pesquisadores encontrarem concordância nas respostas.

O conteúdo de cada entrevista foi analisado segundo Bardin. ${ }^{12}$ Foi realizada a classificação alfanumérica composta pela letra "E”, seguida de identificação numérica de 1 a 9 , referentes à ordem em que foram entrevistados; o tratamento e interpretação dos resultados obtidos permitiram a relação entre o conteúdo manifesto nos discursos e a literatura científica pertinente.

A pesquisa foi aprovada por Comitê de Ética cadastrado no Conselho Nacional de Saúde (CAAE - 0578.0.203.000-11).

\section{Resultados e algumas reflexões}

Os fatores clássicos

Na literatura disponível para o planejamento de cardápios, existem fatores clássicos que interferem na criação como os custos, os hábitos alimentares e culturais dos clientes, as características dos restaurantes (localização, horário de funcionamento e tipo de serviço oferecido), as etapas de produção e os ingredientes disponíveis. ${ }^{13-16}$ Nesta pesquisa, de modo geral, todos os entrevistados citaram a técnica de preparo, a qualidade e sazonalidade dos ingredientes, a logística e o limite de produção, a rotatividade dos cardápios e a margem de erro no preparo de um prato como fatores fundamentais para a criação dos cardápios.

Porque não adianta eu criar um prato que eu possa ter margem de erro de $90 \%$ na execução (E1).

Você tem um espaço de estocagem, o limite de quantas coisas você pode preparar e o que a mercadoria vai gerar, vai estar sempre fresca, então não tem como crescer o cardápio indefinidamente (E9).

Os chefes entrevistados estão à frente de restaurantes conceituados e certamente precisam estar atentos a todos os aspectos clássicos e fundamentais no planejamento de cardápios. Contudo, as preocupações técnicas surgem nos discursos entremeadas por inquietações de outra natureza. A satisfação e a receptividade do cliente, fatores preponderantes na decisão sobre a permanência ou a retirada de pratos do cardápio, ajudam a entender que questões subjetivas, que fogem de condutas estritamente técnicas, são relevantes para o chefe na criação de um novo menu.

Na análise do discurso dos chefes, percebeu-se que o planejamento de cardápios é caracterizado por um processo criativo que não se limita aos fatores citados e segue outros percursos, como a proposta do restaurante e a vivência pessoal e profissional do chefe. 


\section{A proposta do restaurante}

A proposta é um dos elementos centrais no processo criativo em restaurantes à la carte. $\mathrm{O}$ tipo de restaurante também depende da vivência do chefe, ou seja, para tal público, o chefe de cozinha define a melhor proposta a partir de suas experiências.

Não adianta eu criar um prato sem ter um perfil do restaurante [...]. Esse perfil está relacionado ao públicoalvo, ao tipo de pratos oferecidos (regional ou contemporâneo), decoração, tipo de louça, o valor do prato e do serviço ofertado. Cada detalhe vai me levar para um lado [...] então é ai que eu vou sentar e vou desenvolver e procurar o mix que vou colocar em meu cardápio (E1).

Nesta pesquisa, ficou evidente que o chefe cria os cardápios a partir das características sociais e culturais de seu público-alvo, com ênfase na valorização da culinária regional. Os chefes entendem que as técnicas de preparo e as bases da cozinha são elementos internacionalizados que devem se voltar para o resgate da cultura alimentar regional, ${ }^{17}$ priorizando os ingredientes e, propriamente, a memória afetiva dos clientes.

Memória afetiva [...] algum prato que vai levá-lo para outro lugar como, por exemplo, sorvete de paçoquinha (E3).

A significação alimentar pode possuir vários eixos de valores, como a memória à tradição, onde a comida teria função rememorativa, o que garantiria a sobrevivência de algumas tradições. As pessoas precisam reconhecer e identificar os alimentos, tarefa cada vez mais difícil no contexto contemporâneo. Por isso, a nostalgia da cozinha caseira permanece fortemente viva, tendo como base a segurança oferecida pelo conhecimento dos ingredientes e de sua forma de preparo. ${ }^{4}$

Nessa direção, Fischler \& Masson ${ }^{18}$ denominam de "sincretismo culinário generalizado" a globalização de produtos e costumes alimentares, os quais geram transformações na composição dos alimentos e nas formas de consumo, levando a uma mundialização dos gostos. No entanto, a modernidade pode em muitos casos favorecer a formação de particularidades locais, questão notoriamente observada em nossa pesquisa. Fonseca et al. ${ }^{4}$ ressaltam que há uma tendência de valorização dos sistemas alimentares nacionais e locais como forma de reforçar as particularidades.

O trabalho dos chefes de cozinha, identificado em nossa pesquisa, pode também ser interpretado como uma resposta ao suposto caráter permeável da nossa cultura vindo da globalização, como discutido por Garcia. ${ }^{19}$ Segundo a autora, pressionada pelo poder aquisitivo, pela publicidade e praticidade, a alimentação torna-se passível de mudanças, culminando nos modos alimentares contemporâneos. No entanto, a cozinha tradicional pode se transformar na cultura mundializada, como uma tradição reinventada, a qual recicla elementos da memória popular, recriando e atualizando elementos do passado que se misturam com o presente. 


\section{A vivência profissional e pessoal}

Nota-se que no processo criativo dos chefes de cozinha é fundamental considerar a vivência pessoal e profissional do chef.

A experiência de vida, não o experimento químico, não um experimento de um laboratório, mas experiência de criar a partir daquilo que você vivencia [...]. É lógico que sempre pegando as referências de tudo que já vi, tentando fazer algo variado para não virar uma cópia (E4).

Segundo Bondía, ${ }^{20}$ "a experiência é aquilo que nos passa, ou que nos toca, ou que nos acontece e, ao nos passar, nos forma e nos transforma. Somente o sujeito da experiência está, portanto, aberto a sua própria transformação". Nos relatos dos chefes, ficou evidente a importância da experiência no seu processo criativo. Essa vivência faz com que eles tenham intuição e sensibilidade para criar e isso vai além dos fatores que a literatura apresenta como preponderantes e técnicos para a criação de novos pratos.

Marcado pela criatividade, o chefe de cozinha realiza um trabalho artístico. Por isso, Lipovetsky ${ }^{11}$ ressalta que a figura do chefe, a gastronomia e os grandes restaurantes jamais foram tão comentados, auscultados, postos em cena pelas mídias, já que a felicidade alimentar não encontra mais sua plena expressão nos banquetes desmedidos, mas na sensualidade da degustação e na busca das qualidades gustativas.

A vivência do profissional - ou seja, suas mais diversas experiências com a cozinha - propicia o conhecimento, o domínio da técnica e o entendimento do desejo do cliente, o que resulta em uma crescente capacidade de criar e transformar novos pratos. Nesse sentido, no processo de criação de um prato, os chefes podem pesquisar um mesmo ingrediente e chegar a resultados próximos ou diferentes, porque a criatividade se dá no trabalho. Ao criar um prato, o chefe intui, age, transforma, e configura algo novo. Segundo Ostrower, ${ }^{21}$ "a todo instante, ele terá que se perguntar: sim ou não, falta algo, sigo, paro... isso ele deduz e pesa-lhe a validez”. Isso só é possível a partir dos conhecimentos que já incorporou em diversos contextos, como os familiares ou profissionais, conforme expresso por um dos entrevistados:

As técnicas são as mesmas, o olhar daquele que está criando é que vai diferenciar (E4).

Esse "olhar" do chefe é o que define um bom restaurante, que vai sempre além de seguir uma fórmula de sucesso e receitas consagradas, amplamente divulgadas e acessíveis a todos os profissionais. 
Muitas vezes a receita é a mesma, mas cada um tem o pulo do gato. Então, para cada situação a receita fica adaptada. Posso até fazer com todos os ingredientes dele... não vai sair a receita igual, mas vou tentar fazer igualzinho. Na semana seguinte, na hora que eu pegar pra fazer aquela receita, eu vou usar meu sentimento. Porque cozinha funciona dessa forma. Cozinha é sentimento (E1).

\section{A emoção do cliente}

A vivência do chefe que cria também é capaz de proporcionar novas vivências para o cliente. O cliente se emociona, se envolve, cria vínculos e isso condiciona, de certa maneira, a proposta do restaurante e a criação dos cardápios.

A refeição entrelaça as diversas esferas da experiência humana individual, como a dos sentidos, dos afetos e da inteligência e, ao mesmo tempo, se apresenta como espaço de encontro e satisfação. A refeição é um evento humanizador por excelência, como uma escola de sentidos, de relacionamentos e de convivência ${ }^{22}$.

A satisfação do outro é muito importante para a gente. Acho que isso é fundamental, porque o cozinheiro gosta disso, principalmente gosta de proporcionar alegria (E5).

Com a satisfação do seu cliente, o chefe se valoriza e cresce profissionalmente, ${ }^{23}$ sobretudo em uma sociedade pós-moderna, em que se buscam exemplos a serem seguidos, e não líderes, pessoas que, sob os refletores, mostram como as coisas que realmente importa são feitas. ${ }^{10}$

O processo de criação tem que ser uma pesquisa sem fim. Eu, pelo menos, sempre gosto [...] de fazer diferente para justamente a pessoa ter essa experiência única, porque, se não, fica tudo igual (E7).

A fidelidade do cliente às criações de um chefe e a nova forma de comer ingredientes já conhecidos têm levado muitas pessoas a frequentar restaurantes com propostas diferenciadas, a descobrir lugares e pratos novos, e a buscar fantasias e originalidade nas refeições. Observa-se uma cultura hedonista sob a lei da variedade, da mudança acelerada, da fantasia espetáculo. ${ }^{11}$ Nesse cenário, a demanda pelo trabalho do chefe tem crescido, o que o faz sempre pensar algo novo, que surpreenda e, ao mesmo tempo, resgate memórias afetivas ligadas ao comer.

A surpresa de ver aquele produto feito de uma forma diferente, de uma forma inusitada, também não deixa de ser uma nova descoberta. Uma parte do papel do chefe inserido na gastronomia é tentar resgatar aqueles produtos que já estiveram na mesa e, que por algum motivo, sumiram (E4). 
Por isso, a criação acompanha todo o trabalho do chefe de cozinha de maneira a atender as expectativas dos clientes, com pratos destradicionalizados que cruzam aromas, deslocando os produtos de sua aparência e de contexto habituais. ${ }^{11}$

Para exemplificar, o agora extinto restaurante elBulli, do renomado chefe catalão Ferran Adrià, que apresentou o maior número de novidades gastronômicas nas últimas décadas, passou a ser não somente um local de alimentação, e sim palco de performances gastronômicas inéditas que apelam a todos os sentidos, apresentações que só podem ser plenamente degustadas se forem seguidas de toda uma direção cênica do pessoal encarregado do serviço, ou seja, cada prato é uma obra de arte. Segundo Adrià, para que o cozinhar se transforme em obra de arte, é preciso que o chefe tenha consciência de que "cozinhar é uma linguagem que pode expressar harmonia, criatividade, felicidade, beleza, poesia, complexidade, magia, humor, provocação e cultura". ${ }^{24}$

Por outro lado, nota-se que a novidade nunca surge no vácuo totalmente, desprendida de tradições, hábitos e convenções. Para atingir o realmente novo, é preciso confrontar-se com o existente e conhecido. ${ }^{24}$ Nesse ponto, o que há de novo é que a figura do chefe de cozinha, e não mais a tradição em si, tornou-se referência.

\section{Consumo moderno da gastronomia}

Mesmo em uma era em que o comer e o beber passam pela reflexividade e pela responsabilidade individual, nas palavras de Lipovetsky ${ }^{11}$ surge uma "cozinha patchwork", que dá tanta importância ao conteúdo do prato quanto à criatividade e à surpresa da descontextualização. A alimentação torna-se sinônimo de entretenimento e pressupõe-se que essas experiências ganham espaço, cada vez mais, no cotidiano. Vimos surgir um novo comensal, e esse cenário abre novas possibilidades para novos gostos e sabores, ingredientes e aquece o mercado da gastronomia como, por exemplo, o crescimento de supermercados especializados denominados gourmet, sempre vinculados à figura do chefe - que, neste caso, propõem que o comensal incorpore a criatividade desse ator social.

A intensa midiatização da gastronomia expressa no aumento do número de veículos como livros, revistas, cadernos de grandes jornais, programas televisivos com chefes celebridades e sítios eletrônicos ${ }^{25}$ pode ser um indicativo de novos modos alimentares. Ademais, percebe-se grande procura por cursos de ensino superior em gastronomia. ${ }^{26} \mathrm{Em}$ ambos os casos, percebe-se o convite a uma cultura pós-moderna cuja referência é selecionada pelo próprio indivíduo, dentre muitas opções que lhe são apresentadas, e que ele mesmo pode criar. 


\section{Considerações finais}

Todas essas questões aqui discutidas colaboram para o crescimento e disseminação de novos hábitos, os quais impactam diretamente no consumo alimentar e sugerem um novo olhar para os modos de consumo contemporâneos. Um olhar que perceba mais a importância do chefe de cozinha em detrimento das tradições ou condutas alimentares adequadas e, até mesmo, tendências generalizantes.

Por fim, o processo criativo dos chefes e, consequentemente, sua influência nos novos modos alimentares da contemporaneidade, pode indicar um novo percurso para os estudos relacionados ao comportamento alimentar. Constatou-se que, em tempos de modernidade alimentar, a criatividade, a vivência pessoal e profissional e a emoção por ele provocada no cliente são fundamentos do trabalho do chefe de cozinha.

\section{Referências}

1. Moreira SA. Alimentação e comensalidade: aspectos históricos e antropológicos. Ciência e Cultura 2010; 62(4):23-26.

2. Associação Brasileira das Empresas de Refeições Coletivas [Internet]. Mercado real [acesso em: ago. 2013]. Disponível em: http://www.aberc.com.br/mercadoreal.asp?IDMenu=21.

3. Instituto Brasileiro de Geografia e Estatística. Pesquisa de orçamentos familiares 2008-2009: análise do consumo alimentar pessoal no Brasil. Rio de Janeiro: IBGE; 2011.

4. Fonseca AB, Souza TSN, Frozi DS, Pereira RA. Modernidade alimentar e consumo de alimentos: contribuições antropológicas para a pesquisa em nutrição. Ciên. Saúde Coletiva 2011; 16(9):3853-3862.

5. Federação das Indústrias do Estado de São Paulo. Brasil food trends 2020. São Paulo: FIESP; 2010.

6. Fernández-Armesto F. Comida: uma história. Rio de Janeiro: Record; 2010.

7. Flandrin JL, Montanari M. História da alimentação. São Paulo: Estação Liberdade; 1998.

8. Shore E. Jantando fora: o desenvolvimento do restaurante. In: Freedman P. organizador. A história do sabor. São Paulo: SENAC; 2009. p. 301-331.

9. Proença RPC. Alimentação e globalização: algumas reflexões. Ciência e Cultura 2010; 62(4):43-47.

10. Bauman Z. Modernidade líquida. Rio de Janeiro: Jorge Zahar; 2001.

11. Lipovetsky G. A felicidade paradoxal: ensaio sobre a sociedade de hiperconsumo. São Paulo: Companhia das Letras; 2007.

12. Bardin L. Análise de conteúdo. Lisboa: Edições 70; 2011.

13. Abreu ES, Spinelli MGN, Pinto AMS. Gestão de unidades de alimentação e nutrição: modo de fazer. $2^{a}$ ed. São Paulo: Metha; 2007. 
14. Riggiolli MR. Planejamento estratégico de cardápios. 2ª ed. São Paulo: Atheneu; 2010.

15. Teichmann IM. Cardápios: técnicas e criatividade. 6ª ed. Caxias do Sul: EDUCS; 2007.

16. Barreto RLP. Passaporte para o sabor. 5a ed. São Paulo: Senac-SP; 2004.

17. Rambourg P. Historie de la cuisine et de la gastronomia françaises. Paris: Perrin; 2010.

18. Fischler C, Masson E. Comer: a alimentação de franceses, outros europeus e americanos. São Paulo: SENAC; 2010.

19. Garcia RWD. Reflexos da globalização na cultura alimentar: considerações sobre as mudanças na alimentação urbana. Revista de Nutrição 2003; 16(4):483-492.

20. Bondía JL. Notas sobre a experiência e o saber de experiência. Revista Brasileira de Educação 2008; 19:20-28.

21. Ostrower F. Criatividade e processo de criação. Petrópolis: Vozes; 2005.

22. Gallian DMC. A desumanização do comer. Estudos Avançados 2007; 21(60):179-184.

23. Assunção MP. O fazer do cozinheiro. In: Freitas MCS, Fontes GAV, Oliveira N. organizadores. Escritas e narrativas sobre alimentação e cultura. Salvador: EDUFBA; 2008. p. 111-128.

24. Trefzer R. Clássicos da literatura culinária: os mais importantes livros de gastronomia. São Paulo: SENAC; 2009.

25. Scholliers P. Inovação e tradição: o novo cenário da gastronomia. In: Freedman P. organnizador. A história do sabor. São Paulo: SENAC; 2009. p. 333-357.

26. Brasil. Ministério da Educação e Cultura [Internet]. Cadastro da educação superior. [acesso em: 24 out. 2013]. Disponível em: http://emec.mec.gov.br/. 